\title{
Wolf s Isotopic Response: A Case of Metastatic Gastric Adenocarcinoma
}

\author{
Shatila Torabi, Bita Kiafar, Yeganeh Ramazani and Emadodin Darchini-Maragheh* \\ Cutaneous Leishmaniasis Research Center, Mashhad University of Medical Sciences, Iran
}

Submission: November 18, 2021; Published: December 03, 2021

*Corresponding author: Dr. Emadodin Darchini-Maragheh, M.D, Resident of Dermatology, School of Medicine, Mashhad University of Medical Sciences, Mashhad, Iran

\section{Abstract}

Wolf's isotopic response is defined as the occurrence of a new skin disease at the site of a previous treated or untreated skin disease, mostly herpes zoster. A 70-year-old man, presented with persistent lesions at the same location of previously healed herpes zoster infection. Histopathology revealed diffuse infiltration of signet-ring form neoplastic cells. Further evaluations confirmed gastric adenocarcinoma in the patient. Rare etiologies of Wolf s isotopic response should be known by physicians and early histopathologic assay when face to this phenomenon in order to early diagnosis is essential.

Keywords: Wolf s isotopic response; Herpetic disease; Hematologic malignancies; Gastric fundus ulcer; Perigastric lymph nodes; Thrombophlebitis, Mucinous adenocarcinoma

\section{Introduction}

Wolf s Isotopic Response (WIR) refers to a new skin disease, appears at the same location (isotopic) of previously healed and unrelated skin condition. The initial skin disease in most of cases is herpes zoster [1]. WIR was first described in 1955. There is fine difference between WIR and Koebner's isomorphic response. Koebner's isomorphic response describes the appearance of same existing skin lesion arising at a site of damaged or traumatized skin [2]. Whenever the isotopic response follows a herpetic disease, the phenomenon is named as Post-Herpetic Isotopic Response (PHIR) [2].
After the initial skin herpes disease has healed, a wide variety of dermatoses can be detected on the same site, which mainly include granuloma annulare, furunculosis, pseudolymphoma, sarcoidal granuloma, tuberculoid granuloma, granulomatous vasculitis, skin malignancies (non-melanoma and melanoma skin cancers), hematologic malignancies (leukemia, lymphoma), solid organ malignancies, etc. [1-4]. Table 1 demonstrates cutaneous disorders that can develop within sites of herpes zoster. Skin metastasis has been infrequently reported to present as WIR.

Table 1: Cutaneous disorders that can develop within sites of herpes zoster (Wolf's Isotopic Response) [1-5].

\begin{tabular}{|c|c|}
\hline Cutaneous Disorders & Explanation \\
\hline Acneiform & Comedones; Furunculosis; Rosacea \\
\hline Dermatitis & Granuloma anulare; Granulomatous dermatitis (sarcoidosis, tuberculoid); Granulomatous vasculitis \\
\hline Granulomatous & Hematologic (Lukemia, lymphoma cutis); Kaposi sarcoma (HIV associated form); Angiosarcoma; Solid organ metas- \\
\hline Infiltrative & tases (Breast cancer, Ovarian cancer) \\
\hline Malignant & Psoriasis; lichen planus; Lichenoid GVHD \\
\hline Papuloesquamous & Lichen sclerosus; Morphea; Hypertrophic scar/kelloid \\
\hline Sclrosing & Trophic syndrome (trigeminal, cervical) \\
\hline Ulcerative & Acquired perforating disorders; Tinea; Bullous pemphigoid \\
\hline Miscellaneous &
\end{tabular}




\section{Juniper Online Journal of Case Studies}

\section{Case Report}

A 70-year-old man was admitted at the department of Internal Diseases due to severe lethargy and weight loss and examined by a dermatologist through a consultation. The patient presented with a two-month history of erythematous firm pinkish papules and nodules along lateral thoracic dermatome of his left shoulder, in the same location as previously healed herpes zoster infection, which was resolved after treatment with oral valacyclovir one year ago (Figure 1). No vesicle or blister was observed. No pain or dysesthesia was present. Further skin examination revealed no related dermatosis. The patient mentioned history of neglected gastric fundus ulcer since 2 years ago.
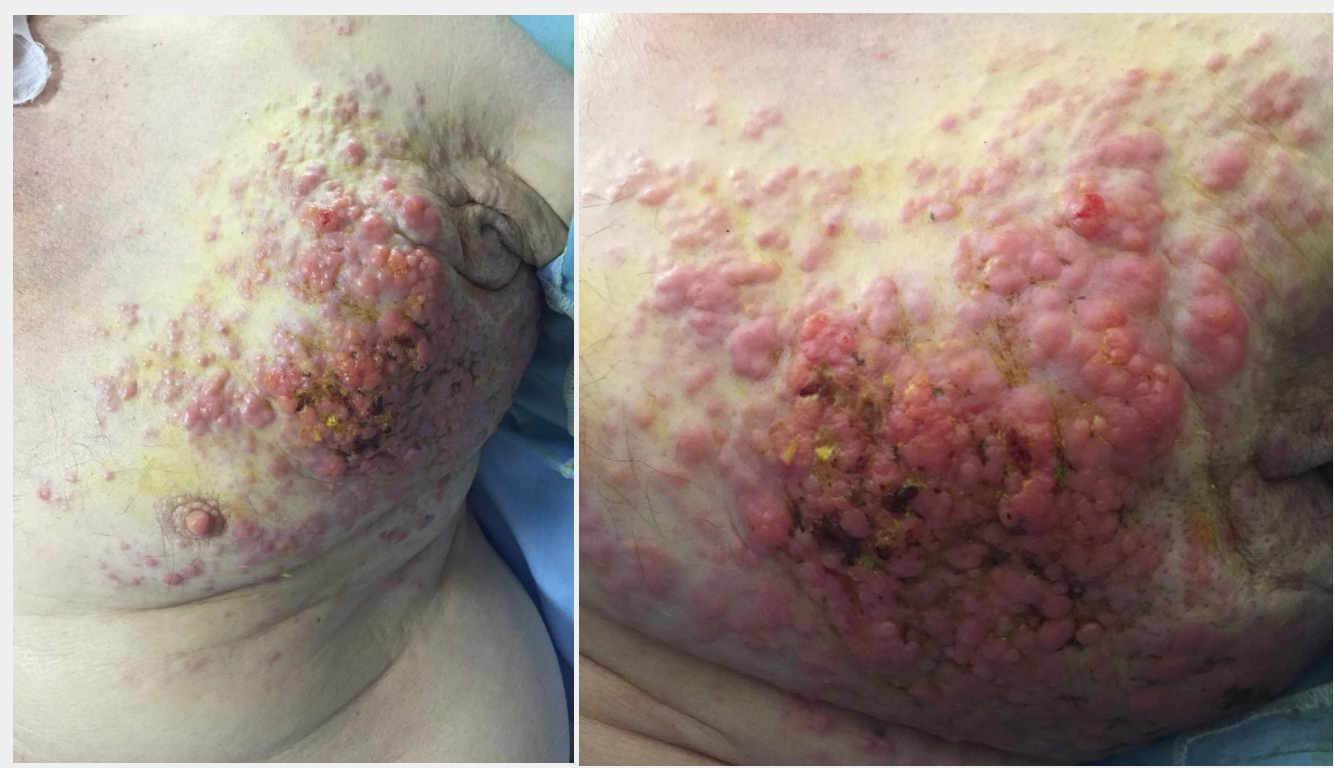

Figure 1: Wolf's Isotopic response at the site of previous herpes zoster infection: erythematous firm pinkish papules and nodules along lateral thoracic dermatome of left shoulder.

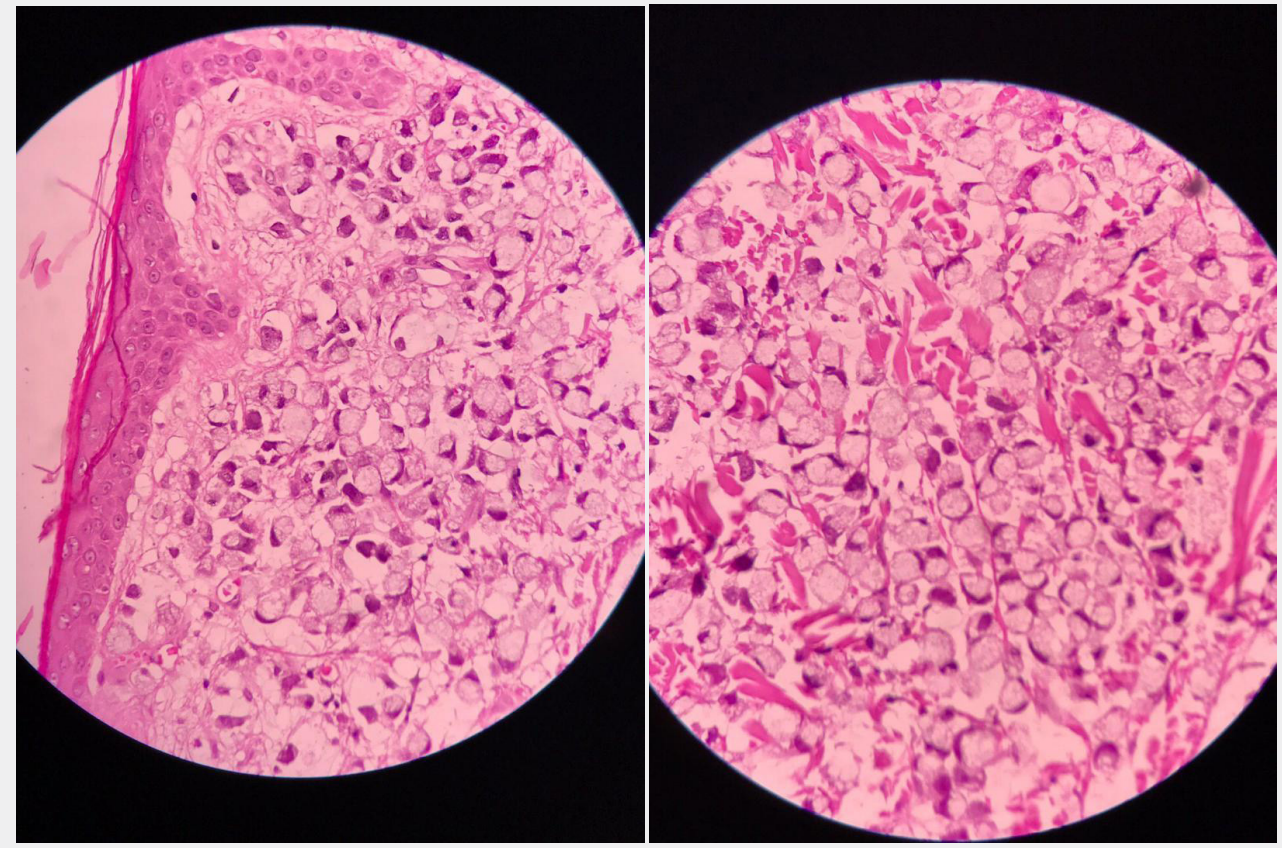

Figure 2: The infiltration of the skin by poorly differentiated signet-ring form neoplastic cells that originated from gastric adenocarcinoma (H\&E200). 
Regarding physical examination, two incisional skin biopsies were performed, suspicious to skin metastasis or granulomatous lesions. Histological assays revealed diffuse infiltration of signetring form neoplastic cells within the superficial and deep dermis as well as excess extracellular mucin formation and lymphovascular embolic foci, reminiscent of mucinous adenocarcinoma (Figure 2). The patient underwent lower and upper endoscopy in the same admission and histologic examination of resected gastric fundus mass revealed poorly differentiated adenocarcinoma with signet-ring cells.

The tumor had invasion into the serosa and perigastric lymph nodes of both curvatures of the stomach, defined as metastatic carcinoma. The patient was classified as stage IIIA (T3N2M0) and referred to the oncologist for appropriate treatment. The skin lesion was shrunk after six sessions of adopting chemotherapy, nevertheless, the patient succumbed to the disease one year after diagnosis of the carcinoma. Written informed consent had been obtained prior to the death.

\section{Discussion}

In most cases of WIRs, the initial dermatosis is herpes zoster, known as PHIR, although other initial dermatosis may be varicella, herpes simplex, or thrombophlebitis [5]. Metastasis of internal organ tumors can be rarely manifests as WIR. Hence, awareness and recognition of this entity, are important for diagnosis.

Among solid organ tumors, breast carcinoma and ovarian carcinoma have been formerly reported to have cutaneous manifestation as PHIR. Previously, Wyburn-Mason has reported cases of breast and laryngeal carcinomas developing at the site of previously healed herpes zoster [6]. More recently, Jaka-Moreno [5] has performed a retrospective study on 9 patients with underlined malignancy who presented by PHIR. Five patients had underline B-cell chronic lymphocytic leukemia, non-Hodgkin lymphoma was diagnosed in two patients, and one had ovarian carcinoma [5].
The pathogenesis of WIR is unknown. Herpes zoster may subsequently damage nerve fibers in the dermis, alter immunity and lead to hyper-reactivity to the inflammatory processes such as granulomatous reaction, or local immunosuppression, leading to tumor infiltration, such as leukemia and other malignancies. Moreover, abnormal angiogenesis caused by the nerve damage may also play role in the pathogenesis [7].

\section{Conclusion}

Clinicians should bewell informed in all feature of herpes zoster, including PHIR; so, in this literature, we highlight the importance of skin punch biopsies when face with WIR phenomenon. In aggregate, this article especially points out rare malignant etiology of PHIR which can be new and useful. To our knowledge, this is the first reported case of gastric adenocarcinoma manifested as PHIR.

\section{References}

1. Wang T, Zhang M, Zhang Y, Zhang Y, Zhang S, et al. (2019) Wolf's Isotopic Response after Herpes Zoster Infection: A Study of 24 New Cases and Literature Review. Acta Derm Venereol 99(11): 953-959.

2. Munir S, Abu Jubara D, Abu Jubara M, Antypas C, Petro Sakuma C (2020) A New Skin Manifestation at the Site of a Previously Healed Dermatosis: A Case of Wolf's Isotopic Response. Cureus 12(11): e11381.

3. Lopez N, Alcaraz I, Cid Manas J, Camacho E, Herrera -Acosta E, et al. (2009) Wolf's isotopic response: zosteriform morphea appearing at the site of healed herpes zoster in a HIV patient. J Eur Acad Dermatol Venereol 23(1): 90-92.

4. Gyonlo VM, Kiafar B, Taheri Bojd AR, Sabouri Rad S (2017) Consecutive occurrence of isotopic and isomorphic response in a patient: Patchy granuloma annulare arising in the site of herpes zoster scar and seborrhoeic dermatitis. Australas J Dermatol 58(3): e155-e156.

5. Moreno AJ, Pestaña AL, Núñez ML, Pérez NO, Esturo SV, et al. (2012) Wolf's isotopic response: a series of 9 cases. Actas Dermosifiliogr 103(9): 798-805.

6. Wolf R, Brenner S, Ruocco V, Filioli FG (1995) Isotopic response. Int J Dermatol 34(5): 341-348.

7. Gesierich A, Krahl D, Weiss H, Brocker EB, Rose C (2004) Granulomatous dermatitis following herpes zoster with detection of varicella zoster virus DNA. J Dtsch Dermatol Ges 2(9): 770-772.

\section{Your next submission with Juniper Publishers} will reach you the below assets

- Quality Editorial service

- Swift Peer Review

- Reprints availability

- E-prints Service

- Manuscript Podcast for convenient understanding

- Global attainment for your research

- Manuscript accessibility in different formats ( Pdf, E-pub, Full Text, Audio)

- Unceasing customer service

Track the below URL for one-step submission

https://juniperpublishers.com/online-submission.php 